\begin{tabular}{c} 
International Journal of Engineering \& Technology, 7 (4.13) (2018) 37-42 \\
International Journal of Engineering \& Technology \\
SPC \\
Website: www.sciencepubco.com/index.php/IJET \\
Research paper \\
\hline
\end{tabular}

\title{
Aerodynamic characteristics of a cranked planform blended wing-body aircraft with $40^{\circ}$ sweep angle
}

\author{
A M Ahmad ${ }^{1}$, R E M Nasir ${ }^{1, *}$, Z A A Latif ${ }^{1}$, W Kuntjoro ${ }^{1}$, W Wisnoe ${ }^{1}$, I S Ishak ${ }^{2}$ \\ ${ }^{1}$ Aviation Technology Research Group, Flight Technology and Test Centre (FTTC), Faculty of Mechanical Engineering, Universiti \\ Teknologi MARA, 40000 Shah Alam, Selangor, Malaysia. \\ ${ }^{2}$ AEROLAB, Dept. Of Aeronautical, Automotive and Ocean Engineering, Faculty of Mechanical Engineering, \\ Universiti Teknologi Malaysia, 81310 Skudai, Johor, Malaysia. \\ *Corresponding author E-mail: rizal524@ salam.uitm.edu.my
}

\begin{abstract}
Baseline 7 Blended Wing-Body design is introduced to study the behaviour of the control surfaces, given four elevons without vertical stabilizer and wingtip. The objective of the paper is to obtain an aerodynamic characteristic of a cranked planform blended wing-body aircraft. The airfoil used for the entire body is NACA 2412, which is selected for ease of fabrication process. The wingspan of the model is $1.4 \mathrm{~m}$ with $0.2 \mathrm{~m}$ thickness. The sweep angle of the model is fixed to $40^{\circ}$. The wingspan area is calculated at $0.405 \mathrm{~m}^{2}$. The experiment is conducted at UTM-LST Wind Tunnel, AEROLAB, Skudai, Johor with test wind speed of $15 \mathrm{~m} / \mathrm{s}$. The maximum lift-to-drag ratio for the model is found to be around 21.9, which is better than many conventional aircraft. Nonetheless, the parabolic regression made to the drag versus lift plot only yields maximum lift-to-drag ratio of 10.0. The value of drag coefficient at zero lift is 0.012 while the maximum lift coefficient found is at 0.65 at $15^{\circ}$ angle of attack. The lift-to-drag ratio improves $38.3 \%$ from 15.9 in the previously-published design. The neutral point is found to be located at $30.6 \%$ of the mean geometric chord in front of the wind tunnel model reference center or about $0.398 \mathrm{~m}$ from the nose of the $0.63 \mathrm{~m}$ long aircraft model or at $63.1 \%$ of aircraft length from the nose.
\end{abstract}

Keywords: blended-wing body; aerodynamics; wind tunnel test; experimental aerodynamics.

\section{Introduction}

The Blended Wing-Body (BWB) aircraft, by its unique configuration and potential benefits, is highly well-suited for the role of an environmentally friendly, long range, high capacity airliner [1]. In the meantime however, the issues of flight stability and control of BWB need to be addressed and solved. The BWB tends to have poor departure characteristics due to its lower maximum lift coefficient that results from the absence or limited numbers of high lift devices and tails with long moment arm [2]. The tailless nature of BWB aircraft with multiple elevons as control surfaces requires an understanding of their impact to its stability, and therefore a BWB aircraft usually requires an active flight control system [2-4].

A study on BWB Unmanned Aerial Vehicle (UAV) has begun in UiTM since 2005, focusing on the design and fundamental aerodynamics and flight dynamics of small BWB $[4,5]$. Based on the studies by Wisnoe et al., it has been found that BWB aircraft having a planform configuration similar to the one that has been previously researched and published by several other researchers does not guarantee the aircraft to have efficient aerodynamics in term of lift-to-drag ratio [5]. The studies conducted in UiTM using its own BWB configuration has found that the BWB has advantages and disadvantages, whereby the BWB aircraft can be a more efficient flying machine but at the expense of its stability [6].

Baseline 7 BWB design is initially introduced to study the behaviour of the control surface, given 4 elevons without vertical stabilizer and no wingtip [7]. The challenge for this BWB design is that the aircraft should fly with improved stability solely depending on airfoil selection and four control surfaces to stabilize the aircraft thoroughly [8-12]. The tail-less design should simplify the mechanism while improving the design characteristics of the Baseline 7 [7]. The objective of this paper is to obtain aerodynamic characteristic of the cranked planform blended wing-body aircraft with $40^{\circ}$ sweep angle through an experimental analysis conducted at UTMLST Aerolab, Skudai, Johor.

\section{Theoretical Framework}

The four forces of flight consist of lift, weight, thrust and drag are denoted by $L, W, T$ and $D$, respectively. They are as illustrated in Figure 1 and Figure 2. The freestream velocity, $V_{\infty}$ is always in the direction of local flight path and therefore, it is presumed that the drag and lift are perpendicular to each other [13].

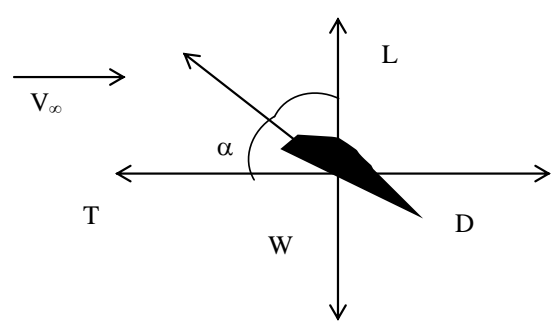

Fig. 1: Forces projected into the plane from free-stream velocity 


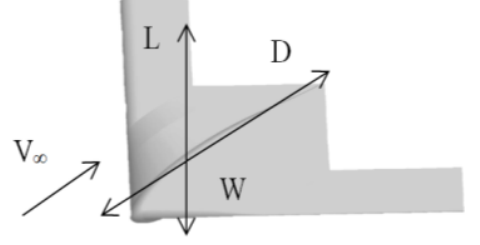

Fig. 2: Four forces of flight shown on the tailless cranked BWB model under study

The equation of motion for an airplane is a statement from Newton's Second Law of Motion as given in Eqn. 1 [14].

$\sum F_{x}=m a_{x}, \quad \sum F_{z}=m a_{z}, \quad a_{x}=a_{z}=0$

The equation signifies the vector equations, $F$ stands for force and $a$ is for acceleration, both are vector quantities. The equation of motion for the parallel force to the flight path is determined directly through the vertical forces including changes of pitch of the airplane [14]. The equation of motion of thrust, $T$ is equal to drag, $D$, same goes to weight, $W$ is equal to lift, $L$. These phenomenon can only exist when the plane endure a free-flight with steady condition [14].

$T=D=\frac{1}{2} \rho V_{\infty}^{2} S C_{D}$

$W=L=\frac{1}{2} \rho V_{\infty}^{2} S C_{L}$

The value of density, $\rho$ always change with respect of altitude of the plane itself. The value of free-stream velocity $V_{\infty}$ also correlates with the speed of the airplane. Lift coefficient, $C_{L}$ and drag coefficient, $C_{D}$ are derived with the value of aerodynamic characteristic of the plane with relation to its design and pressure difference. The value of wingspan area, $S$ is not least important value to determine an airplane's aerodynamic coefficient $[13,15,16]$.

$M=\frac{1}{2} \rho V_{\infty}^{2} S \bar{c} C_{M}$

Lift coefficient behaviour within linear lift region is expected to be linear as indicated in Eqn. 5, where $\frac{d C_{L}}{d \alpha}, \alpha$ and $C_{L o}$ are lift curve slope, angle of attack (pitch angle) and lift coefficient at zero angle of attack, respectively.

$C_{L}=\frac{d C_{L}}{d \alpha} \alpha+C_{L o}$ (within linear lift range)

Meanwhile, the drag polar, or the relationship of drag with respect to lift coefficients, is assumed to be parabolic as shown in Equation 6 , where $k=1 /(\pi e A R)$ or lift-induced drag constant, $k^{\prime}$ are wing-body cambered lift-induced drag constant and $C_{D o}$ is drag coefficient at zero lift.

$C_{D}=k C_{L}^{2}+k^{\prime} C_{L}+C_{D o}$

There is a simpler version of the relation where $k^{\prime}=0$ but it usually happens to 'non-cambered' airplanes (i.e. aircraft with thin, low incidence wing and straight fuselage). In case of BWB, from author's experience, $k^{\prime}$ is often a negative non-zero value. The trend of lift and drag affects the plot of lift-to-drag ratio versus lift coefficient relationship as indicated in Eqn. 7.

$L / D=\frac{C_{L}}{C_{D}}=\frac{C_{L}}{k C_{L}^{2}+k^{\prime} C_{L}+C_{D o}}$

Maximum $L / D$ is found when the change of $L / D$ with respect to $C_{D}$ is zero or similarly the change of $D / L$ with respect to $C_{L}$ is zero, as shown in Eqn. 8.

$\frac{d(D / L)}{d C_{L}}=k C_{L}+k^{\prime}+\frac{C_{D o}}{C_{L}}=0 \rightarrow C_{\text {Lopt }}$ at $(L / D)_{\max }$
Hence the optimal lift coefficient becomes as in Eqn. 9.

$C_{\text {Lopt }}=-\frac{k^{\prime}}{2 k} \pm \sqrt{\left(\frac{k^{\prime}}{2 k}\right)^{2}-\frac{C_{D o}}{k}}$

The large lift produced by the BWB aircraft has a profound impact on pitch moment as given by Eqn. 10

$C_{M}=\frac{d C_{M}}{d C_{L}} C_{L}+C_{M o}=-K_{n} C_{L}+C_{M o}$

The slope of pitch moment-lift coefficients plot is the negative of static margin $K_{n}$, a distance in fraction of mean chord $\bar{c}$ (or reference length) of stick-fixed neutral point (or aerodynamic centre of the BWB aircraft) to the centre of gravity or, in this case, wind tunnel model reference centre. For the purpose of this experiment, mean geometric chord is chosen as $\bar{c}$. To ensure stability, the moment-lift slope must be negative with positive moment at zero lift coefficients $C_{M o}$ to ensure the aircraft trims at angle of attack that produces positive lift.

Static margin has important effect to stability of any aircraft and is especially crucial for a tail-less BWB aircraft due to the large area of lifting surface, therefore a high lift force and longer mean chord, such that a slight change in centre of gravity will affect the moment-lift slope and changes trim angle of attack and cruising velocity. To make matter worse, the change of static margin changes the stability i.e. moving the centre of gravity back and close to the neutral point can reduce the nose-down moment that naturally correct itself to its equilibrium (trim) angle of attack, making the correction process much slower than that for the original centre of gravity location. In a more adverse situation, the moment-lift slope changes to positive, which means unstable behaviour where a slight perturbation in vertical airspeed (or change in angle of attack) causes nose-up motion that will not be corrected naturally but instead continues to pitch up until the aircraft stalls. A BWB aircraft has the tendency to become unstable in pitch motion due to large lift force and short body length without tail that is making the aircraft even more sensitive to perturbations such as wind gust and slight elevons input.

\section{Aircraft model and experiment setup}

The BWB aircraft in this study is modelled in CATIA V5 R20. The wind tunnel model size is the same as the actual size of the BWB aircraft, which is designed to be a small UAV. The aerofoil used for the entire body and wing is NACA 2412. The model's wingspan is $1.4 \mathrm{~m}$ with $0.2 \mathrm{~m}$ thickness at the centre section. The sweep angle of the model is $40^{\circ}$ as illustrated in Figure 3.

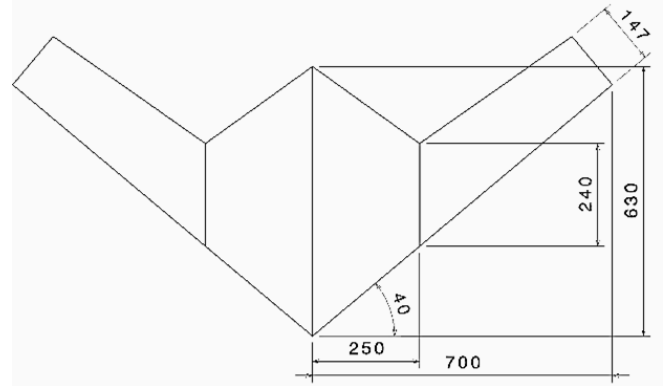

Fig. 3: Full scale model of Baseline 7 and its dimensions

Initially, the Baseline 7 is designed at angle $45^{\circ}$ sweep angle as mentioned in previous publication [6]. In this experiment, the sweep angle of the wing has been modified to $40^{\circ}$ to identify if the sweep angle reduction of $-5^{0}$ will give major differences in aerodynamic coefficients. This includes the wingspan as this model of BWB configurations is designed for generalization and simplicity. The wingspan area is $0.405 \mathrm{~m}^{2}$ while the volume of the model is $0.008 \mathrm{~m}^{3}$, which is calculated using the feature in CATIA suite. 
The mean geometric chord of the model is $0.29 \mathrm{~m}$, hence the aspect ratio of this aircraft is around 4.8.

The UTM-LST AEROLAB is located at Universiti Teknologi Malaysia. The wind tunnel is a close-loop type as depicted in Figure 4 . The wind tunnel can be operated up to $100 \mathrm{~m} / \mathrm{s}$ of airspeed but nominal speed to operate is about $80 \mathrm{~m} / \mathrm{s}$. The force balance used in this wind tunnel is of six-component type with three mounts connected to a large turntable that measures lift, drag, side forces as well as pitch, roll and yaw. These parameters measurement is done automatically by the computer processor located within the vicinity of the AEROLAB as shown in Figure 5. The model is mounted on the three-piece struts protruding from the turntable in which its variable length rear strut can be adjusted to change model pitch angle. Zero-tare pitch angle is initiated using inclinometer as shown in Figure 6.

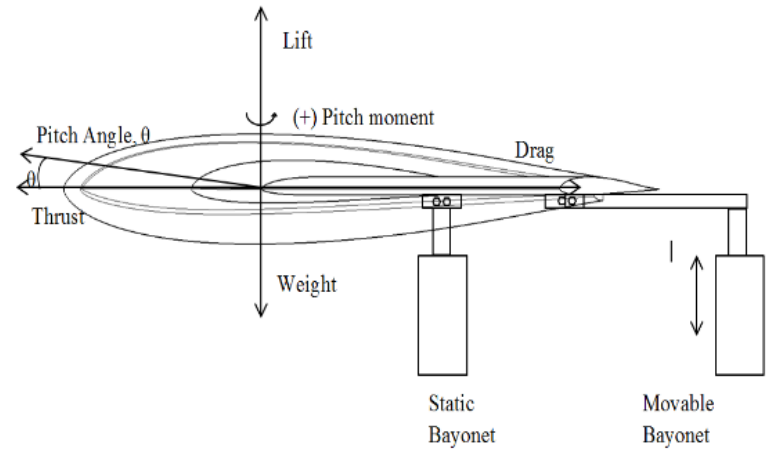

Fig. 4: Schematic diagram of model inside wind tunnel

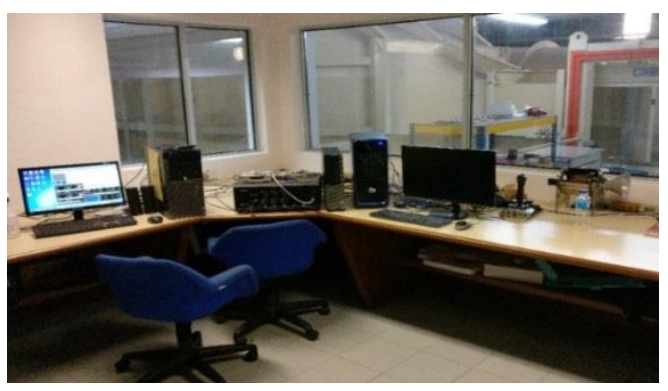

Fig. 5: Control room of wind tunnel

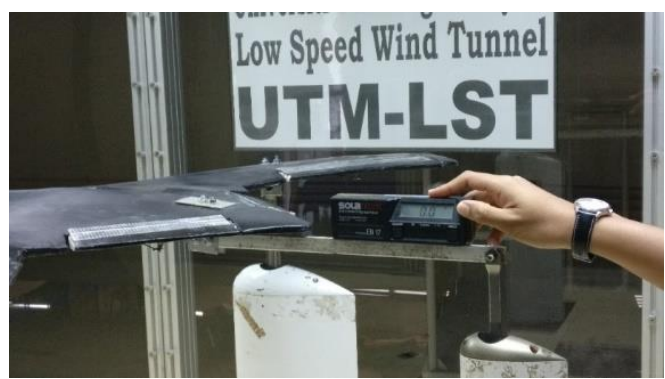

Fig. 6: Model is placed and zero tare method is performed

The experiment is conducted at the airspeed of $15 \mathrm{~m} / \mathrm{s}$ or around $50 \mathrm{~km} / \mathrm{h}$ to reflect the small and light UAV optimal design flight speed, which corresponds to Reynolds number of $R e=263000$ based on mean geometric chord as its reference length. This Reynolds number is higher than $R e=1.0 \times 10^{5}$ for maximum flatplate laminar flow value but less than $5.0 \times 10^{5}$ for minimum flatplat turbulent flow value. It is assumed that the reference flow is considered turbulent although the Reynolds number may suggest it is in transition between laminar and turbulent. The four control surface of the model (two elevons each side) can be deflected $+10^{\circ}$ upward but in this case, they are all fixed at zero deflection angle as shown in Figure 7. In this paper, the effect of angle of attack on the forces and moment coefficients of the baseline model (with all elevons deflection set to 0.0 degrees) is analyzed to find the aircraft optimal flight condition where the highest lift-to-drag ratio occurs. In addition, the important characteristics of the aircraft's aerodynamics, especially the lift-curve plots, drag polar, pitch moment stability and the neutral point location are also of high interest.

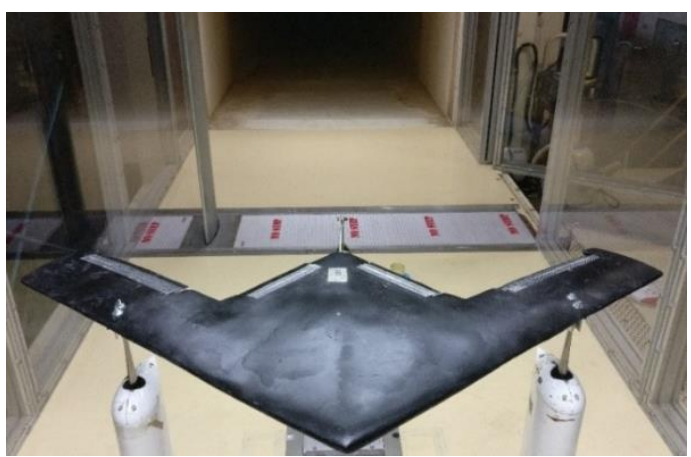

Fig. 7: Finalized position of model inside wind tunnel

\section{Correction factor}

The experiment is conducted in wind tunnel with closed-loop system, which means an extra calculation for corrections must be implemented in order to have more accurate aerodynamic characteristics [17]. The values obtained in a closed-system wind tunnel must be corrected through several effects of interference corrections including the solid blockage, wake blockage and streamline curvature correction [18]. The influences of tunnel walls and its interactions between tunnel wall and model will alter the end result of the aerodynamic characteristics [18].

The first correction calculation is by implementing a solid blockage correction that is a simple velocity correction of which the flow of air inside the wind tunnel will be in freestream condition. The solid blockage sometimes can be neglected due to its minimal correction of velocity of the air flows that is affected during the solid blockage correction [19]. The correction is made based on Eqn. 11 where $\Delta V$ is the corrected velocity of the airspeed, $\varepsilon_{s b}$ is the solid blockage factor and $V_{u}$ is the uncorrected velocity of the airflow at the leading edge. Additionally, $\varepsilon_{s b}$ is calculated using Eqn. 12 where $V_{b}$ is the volume of the model, $K_{l}$ for vertical model is 0.52 and $S$ is the working section area.

$\Delta V=\varepsilon_{s b} V_{u}$

$\varepsilon_{s b}=\frac{K_{1} V_{b}}{S^{3 / 2}}$

The wake correction, on the other hand, carries out a handful of the corrected parameters like wake correction factor and velocity of airflow at trailing edge of the model, as given by Eqn. 13 and Eqn. 14, where $c_{d_{u}}$ is uncorrected drag coefficient, $c$ is the model's length and $h$ is the height of working section.

$\Delta V=\varepsilon_{w b} V_{U}$

$\varepsilon_{w b}=\frac{c}{2 h} c_{d_{u}}$

Streamline curvature correction involves the correction of the drag coefficient, lift coefficient, angle of attack and moment coefficient as the Eqn. 15 to Eqn. 18 cover these aerodynamic characteristics, where $\propto$ is the corrected angle of attack, $\alpha_{u}$ is uncorrected angle of attack, $C_{l}$ is corrected lift coefficient, $C_{l u}$ is uncorrected lift coefficient, $C_{m 1 / 2 u}$ is uncorrected moment coefficient halved, and $\sigma$ is sigma, $\sigma$. The wind tunnel wall has been artificially curved to form a curvature streamline inside the system and thus needs to be corrected to achieve better results from wind tunnel closed system experimental procedure [20]. 


$$
\begin{aligned}
& \propto=\propto_{u}+\frac{57.3 \sigma}{2 \pi}\left(C_{l u}+4 C_{m 1 / 2 u}\right) \\
& C_{l}=C_{l u}(1-\sigma-2 \varepsilon) \\
& C_{m 1 / 2}=C_{m \frac{1}{2} u}(1-2 \varepsilon)+\frac{\sigma C_{l}}{4} \\
& \sigma=\frac{\pi^{2}}{48}\left(\frac{c}{h}\right)^{2}
\end{aligned}
$$

Total corrected airspeed is given in Eqn. 19, where $\varepsilon$ is summation of solid blockage factor and wake blockage factor.

$V=V_{u}(1+\varepsilon)$

In the meantime, total corrected drag is obtain by Eqn. 20, where $C_{d c}$ is corrected drag coefficient and $C_{d u}$ is uncorrected drag coefficient.

$$
C_{d c}=C_{d u}\left(1-3 \varepsilon_{s b}-2 \varepsilon_{w b}\right)
$$

\section{Result and discussion}

Table 1 presents the results of experiment that have been corrected for blockages. Figures 8 to 11 are the plots of lift coefficient, drag coefficient, moment coefficient and lift-to-drag ratio, respectively. From these plots, the best pitch angle to achieve the maximum lift to drag ratio is at $5^{0}$ angle of attack (pitch angle). Drag coefficient and pitch moment coefficient graphs are plotted against lift coefficient to indicate the drag and pitch moment behaviour in relation to lift coefficient.

Table 1: Corrected value of aerodynamic characteristics

\begin{tabular}{|c|c|c|c|c|c|c|}
\hline $\mathbf{U}(\mathbf{m} / \mathbf{s})$ & $\left.\boldsymbol{\alpha} \mathbf{(}^{\mathbf{0}}\right)$ & $\mathbf{C L}$ & $\mathbf{C D}$ & $\mathbf{C M}_{\mathbf{W T}}$ & $\mathbf{C M}_{\mathbf{C} / \mathbf{4}}$ & $\mathbf{L / D}$ \\
\hline 15.024 & -9.99 & -0.313 & 0.052 & -0.073 & -0.005 & -6.1 \\
\hline 15.024 & -5.01 & -0.138 & 0.030 & -0.078 & -0.048 & -4.6 \\
\hline 15.024 & -0.01 & 0.057 & 0.026 & -0.012 & -0.024 & 2.1 \\
\hline 15.024 & 2.99 & 0.185 & 0.036 & 0.017 & -0.023 & 5.2 \\
\hline 15.024 & 4.99 & 0.270 & 0.012 & 0.056 & -0.001 & 21.9 \\
\hline 15.024 & 6.98 & 0.351 & 0.033 & 0.049 & -0.027 & 10.7 \\
\hline 15.024 & 8.99 & 0.413 & 0.056 & 0.123 & 0.033 & 7.4 \\
\hline 15.023 & 10.98 & 0.511 & 0.068 & 0.121 & 0.010 & 7.6 \\
\hline 15.022 & 12.98 & 0.566 & 0.112 & 0.127 & 0.004 & 5.1 \\
\hline 15.021 & 14.98 & 0.644 & 0.133 & 0.155 & 0.014 & 4.8 \\
\hline 15.020 & 16.97 & 0.586 & 0.170 & 0.099 & -0.032 & 3.4 \\
\hline
\end{tabular}

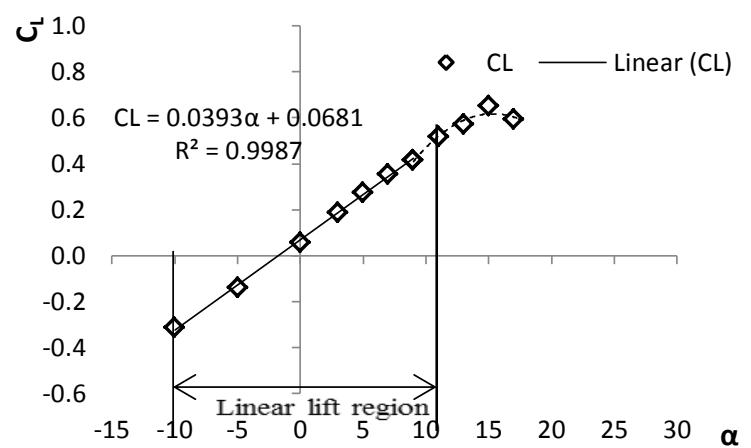

Fig. 8: Lift coefficient versus pitch angle

Based on Figure 8, the trend of lift coefficient with respect to pitch angle is linear and can be approximated using linear regression. It is found that the change of lift with respect to angle of attack within the linear lift region is 0.393 or roughly 0.40 per degree with zero-pitch angle lift coefficient at 0.057 . This is fairly low compared with two-dimensional NACA 2412 aerofoil lift-curve slope of 0.10 per degree and 0.2 , respectively. The maximum lift coefficient of the BWB model here is less than half of two-dimensional
NACA 2412 aerofoil at only 0.65 against 1.50 for the latter, both at pitching angle of $15^{\circ}$. The lift-curve linear region of the BWB model is found to be from $-10^{\circ}$ to $+10^{\circ}$ with lift coefficient values between -0.315 to 0.515 , which is similar to the two dimensional aerofoil's linear lift curve angle of attack range.

There is one possible explanation for this, which is because the aspect ratio of the BWB model is low (i.e. less than 5) whereas many general aviation and commercial aircraft have an aspect ratio of at least 6 and mostly around 8 to 10, discounting sailplanes. The BWB aspect ratio is more in common with fighter aircraft aspect ratio values. However, the BWB aircraft design emphasises more on efficiency of flight, which will be reflected to its range and endurance performance while the mentioned military aircraft design emphasizes on other aspect of performance such as maximum airspeed, rate of climb and rate of turn.

The value of drag coefficient at zero lift is determined from Figure 9, which has the value of 0.012 based on parabolic regressions. This value shows that the BWB design is "sleek" (smooth, low drag) for such configuration without tail and body. However, since the model is within transition flow regime or lower-Reynolds number turbulent flow regime, the drag coefficient is expected to be higher than that of at high Reynolds number of order $10^{7}$ to $10^{9}$, which is common on many airliners and transport aircrafts.

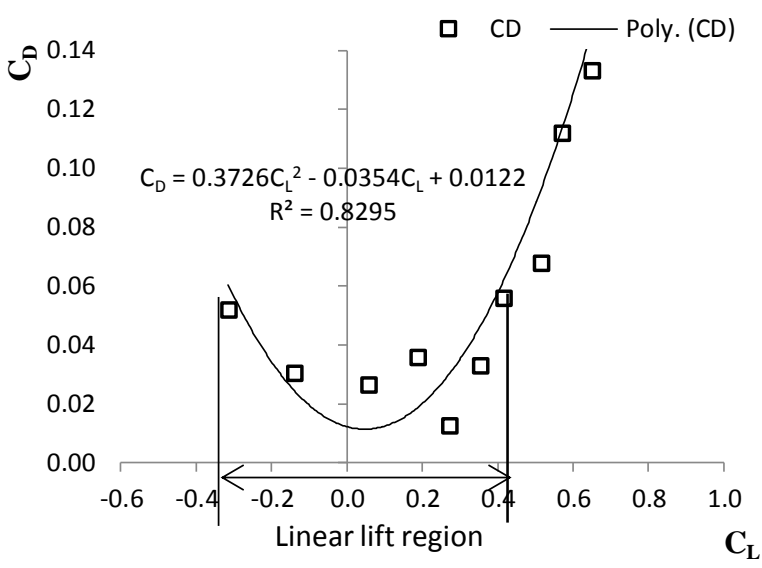

Fig. 9: Drag coefficient versus lift coefficient.

Drag polar equation within linear lift region of this aircraft model is $C_{D}=0.373 C_{L}^{2}-0.035 C_{L}+0.012$. This means the aircraft is of "cambered" wing-body type having additional terms $\left(-0.035 C_{L}\right)$ between $k C_{L}^{2}$ and $C_{D o}$. Since $k=1 /(\pi e A R)$, then the Oswald Efficiency factor, $e$ is found to be 0.177 or $17.7 \%$. This is far lower than estimated $e$ between 0.8 to 1.1 for the ideal wing model. This seems to be consistent to the trend of low lift curve slope and low maximum lift coefficient value of this aircraft but if one look at Figure 10 , then it is found that maximum lift-to-drag ratio is as high as $21.9,38.3 \%$ improvement over the previous BWB design that only gets around 15.9. Regression made to $L / D$ versus $C_{L}$ based on parabolic regression based on Eqn. 6 and Eqn. 7 of $C_{D}$ versus $C_{L}$ shows that maximum lift-to-drag ratio is only around 10.0 at $C_{L}=0.2$ or $3^{0}$ angle of attack. Back to Figure 9, the plot of $C_{D}$ versus $C_{L}$ seems to be hectic with trend that is not actually reflecting parabolic regression shown in Eqn. 6. This looks like poor drag data measurement and according to AEROLAB, 15.0 $\mathrm{m} / \mathrm{s}$ airflow produces forces that fluctuates on the aircraft whether it is due to natural vibrations on the model or the sensitivity of the force balance located below the turntable.

The graph from Figure 11 presents the value of moment coefficient for the model versus lift coefficient. There are two plots on the same graph, namely moment coefficient at wind tunnel experiment reference point and moment coefficient at quarter mean chord point. The former shows that the static margin, which is found from the slope of the linear regression line, is $30.6 \%$ mean chord and this indicates that the wind tunnel reference point is 
$30.6 \%$ of mean chord behind the neutral point of the BWB aircraft or $63.1 \%$ aircraft length that is $0.398 \mathrm{~m}$ behind the nose.

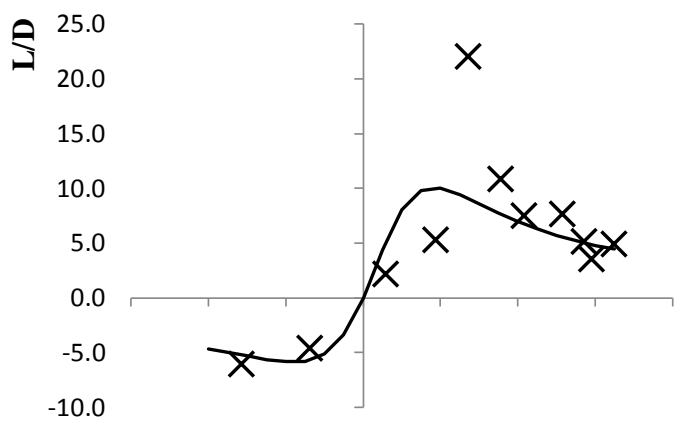

$\begin{array}{llllllll}-0.6 & -0.4 & -0.2 & -1 \mathrm{E}-15 & 0.2 & 0.4 & 0.6 & 0.8\end{array}$

$\mathbf{C}_{\mathbf{L}}$

Fig. 10: Lift-to-drag versus lift coefficient

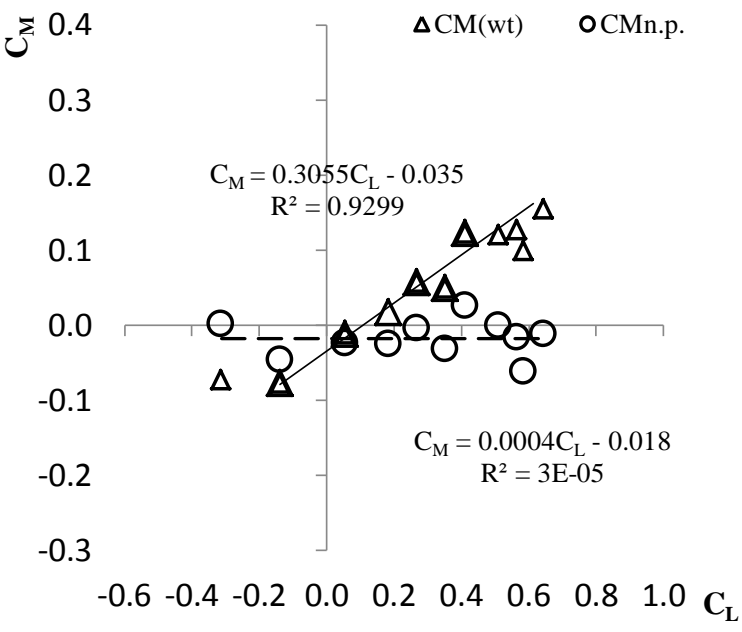

Fig. 11: Moment coefficient versus lift coefficient.

Using established moment transfer method, the reference point is moved to the quarter chord location to plot the pitch moment coefficient versus lift and the result shows that the average slope within the linear lift region is almost zero. This means that the point of the quarter chord is almost similar to the neutral point but with an increased in moment at zero lift values from -0.035 to -0.018 . In actual UAV, the centre of gravity shall be located in front of this point and in order to ensure good stability, the location is recommended to be around 5\% to $10 \%$ mean chord in front of neutral point. Any larger than these will cause a strong nose-down moment (steep negative moment-lift slope) that too much elevons deflection is needed to trim it at a positive lift angle of attack. This is due to the BWB's large lifting area and long mean chord.

To make matter worse, the cranked wing configuration is making its elevons facing $40^{\circ}$ inward or outward and this condition is less effective than having the elevon facing forward towards incoming air. As such, large size elevons are needed to generate nose up moment (by producing downforce at the trailing edge of the wing) and this will surely reduce overall lift of aircraft, increase form drag due to large deflection of elevon and thus reduce the maximum potential lift-to-drag ratio. With the small static margin, the amount of elevon deflection is expected to be smaller than that of large static margin. This shall make it easier to trim the aircraft at higher angle of attack, making the BWB aircraft more agile and enabling it to fly slower and shorten its landing distance. This is particularly crucial when such a small UAV is to be launched by hand and landed on its belly.

\section{Conclusion}

The wind tunnel analysis that is held in Aerolab, UTM is a success and the data has been collected thoroughly. The significance of the experiment is to identify and validate the aerodynamic characteristics for UiTM Baseline 7 design and achieve an understanding over data tabulation, analysis and evaluation. The lift-to-drag ratio that is obtained from this experiment is rather interesting. The analysis is done in the same method from previous research and has seen an improvement of aerodynamic characteristic. The liftto-drag ratio improves from 15.9 to 22.0 as a result of wing sweep reduction from $45^{\circ}$ to $40^{\circ}$ [7] while retaining cranked-wing planform shape. The maximum lift-to-drag ratio occurs at $5^{0}$ angle of attack based on the experiment plot but the regression analysis based on equations presented in this paper only yields a maximum lift-to-drag ratio of 10 at $3^{0}$ angle of attack. The irregularities of data might be caused by the fluctuation of data measured especially on drag coefficient because of its much smaller magnitude compared to lift coefficient. Since a change in wing sweep angle does affect aerodynamic characteristics of the airplane, its neutral point location must also be altered. The neutral point for original Baseline 7 with $45^{\circ}$ wing sweep angle is located at $33.0 \%$ of mean chord in front of the wind tunnel model reference centre but $5^{0}$ sweep angle reduction moves the neutral point backward to only $30.6 \%$ in front of the said reference centre. In terms of aerodynamic performance, it is recommended to redesign the model for ease of production but it should still maintain or improve its aerodynamic efficiency $(L / D)$. The model shall also be tested in wind tunnel that is capable of running at very low speed without generating poor data. However, if the same wind tunnel is to be used again in the next iteration of the experiment, the wind tunnel model should be built half-scale but twice the speed applied for Reynolds number similarity.

\section{Acknowledgement}

The authors would like to express their deepest gratitude to Ministry of Higher Education for granting the research fund related to this experiment (FRGS/1/2016/TK09/UITM/02/1). In addition, our appreciation also goes to the Research Management Institute and the Faculty of Mechanical Engineering, UiTM for various support and facilities provided in this study. Also, a big gratitude to the Aerolab Staff, especially Mr. Basid and his team, for their endless support and guidance in completing the experiment without any hassle and problem.

\section{References}

[1] Shevell RS (1989), Feasibility of the flying wing. Science 245(4924), 1311-1312

[2] Klein V \& Noderer KD (1994), Modeling of aircraft unsteady aerodynamic characteristics. Part 1: Postulated models. NASA Technical Memorandom 109120

[3] Liebeck R, Page M \& Rawdon B (1998), Blended-wing-body subsonic commercial transport. 36th AIAA Aerospace Sciences Meeting and Exhibit

[4] Nasir REM, Kuntjoro W, Wisnoe W, Ali Z, Reduan NF, Mohamd F \& Suboh S (2010), Preliminary Design of "Baseline-II" Blended Wing-Body (BWB) Unmanned Aerial Vehicle (UAV): Achieving Higher Aerodynamic Efficiency Through Planform Redesign and Low-Fidelity Inverse Twist Method. 3rd Engineering Conference on Advancement in Mechanical and Manufacturing for Sustainable Environment

[5] Wisnoe W, Kuntjoro W, Mohamad F, Mohd Nasir RE, Reduan NF \& Ali Z (2010), Experimental results analysis for UiTM BWB baseline-I and baseline-II UAV running at 0.1 mach number. International Journal of Mechanics 4(2), 23-32

[6] Latif MA, Ahmad MA, Mohd Nasir RE, Wisnoe W \& Saad MR (2017), An analysis on $45^{\circ}$ sweep tail angle for blended wing body aircraft to the aerodynamics coefficients by wind tunnel experiment. IOP Conference Series: Materials Science and Engineering 270, 012001 
[7] Nasir REM, Ahmad AM, Latif ZAA \& Kuntjoro W (2017), Experimental result analysis for scaled model of UiTM tailless blended wing-body (BWB) Baseline 7 unmanned aerial vehicle (UAV). IOP Conference Series: Materials Science and Engineering 270, 012005

[8] Wisnoe W, Mohd Nasir RE, Kuntjoro W \& Mamat AMI (2009), Wind tunnel experiments and CFD analysis of Blended Wing Body (BWB) Unmanned Aerial Vehicle (UAV) at mach 0.1 and mach 0.3 13th International Conference on Aerospace Sciences \& Aviation Technology

[9] Coleman T \& Wenkam R (1988), Jack Northrop and the flying wing: the story behind the stealth bomber. New York: Paragon House

[10] Lindhe Norberg UM \& Winter Y (2006), Wing beat kinematics of a nectar-feeding bat, Glossophaga soricina, flying at different flight speeds and Strouhal numbers. J Exp Biol 209, 3887-3897

[11] Siouris S \&Qin N (2007), Study of the effects of wing sweep on the aerodynamic performance of a blended wing body aircraft. Proceedings of the Institution of Mechanical Engineers, Part G: Journal of Aerospace Engineering 221(1), 47-55

[12] Henningsson P, Muijres FT \& Hedenstrom A (2011), Timeresolved vortex wake of a common swift flying over a range of flight speeds. J R Soc Interface 8(59), 807-816

[13] Etkin B \& Reid LD (1996), Dynamics of flight: stability and control. Wiley New York

[14] Anderson JD (1999), Aircraft performance and design. McGrawHill Science/Engineering/Math

[15] Hoerner SF \& Borst HV (1985), Fluid-dynamic lift: practical in formation on aerodynamic and hydrodynamic lift. LA Hoerner

[16] Brumbaugh RW (1994), Aircraft model for the AIAA controls design challenge. Journal of guidance, control, and dynamics 17(4), 747-752

[17] Hensel RW (1951), Rectangular-wind-tunnel blocking corrections using the velocity-ratio method. Southern California Cooperative Wind Tunnel Pasadena

[18] Allen HJ \& Vincenti WG (1944), Wall interference in a twodimensional-flow wind tunnel with consideration of the effect of compressibility. NASA AMES Research Center

[19] Ross I \& Altman A (2011), Wind tunnel blockage corrections: Review and application to Savonius vertical-axis wind turbines. Journal of Wind Engineering and Industrial Aerodynamics 99(5), 523 538

[20] Peckham D \& Atkinson S (1957), Preliminary results of low speed wind tunnel tests on a gothic wing of aspect ratio 1.0. Royal Aircraft Establishment 